\title{
2017 National Standards for Diabetes Self-Management Education and Support
}

Joni Beck, PharmD, BC-ADM, CDE (Co-Chair); ' Deborah A. Greenwood, PhD, RN, BC-ADM, CDE, FAADE (Co-Chair):; Lori Blanton, MS, CHES, CDE; ${ }^{3}$ Sandra T. Bollinger, PharmD, CGP, CDE, FASCP,4 Marcene K. Butcher, RD, CDE; ${ }^{5}$ Jo Ellen Condon, RDN, CDE; ${ }^{6}$ Marjorie Cypress, PhD, C-ANP, CDE; Priscilla Faulkner, MS, MA, CNS, RN, CDE; ${ }^{8}$ Amy Hess Fischl, MS, RDN, LDN, BC-ADM, CDE;

Theresa Francis, MSN, RN, CDE; ${ }^{10}$ Leslie E. Kolb, MBA, BSN, RN; ${ }^{11}$ Jodi M. Lavin-Tompkins, MSN, RN, BC-ADM, CDE:12 Janice MacLeod, MA, RD, LD, CDE; ${ }^{13}$ Melinda Maryniuk, MEd, RD, CDE; ${ }^{14}$ Carolé Mensing, MA, RN, CDE, FAADE; $;^{15}$ Eric A. Orzeck, MD, FACP, FACE, CDE.;6 David D. Pope, PharmD, CDE; $;^{17}$ Jodi L. Pulizzi, RN, CDE, CHC $i^{18}$ Ardis A. Reed, MPH, RD, LD, CDE $i^{19}$ Andrew S. Rhinehart, MD, BC-ADM, CDE, FACP;20 Linda Siminerio, PhD, RN, CDE; ${ }^{21}$ and Jing Wang, PhD, MPH, RN; $; 2$ on behalf of the 2017 Standards Revision Task Force

${ }^{1}$ College of Medicine, University of Oklahoma Health Sciences Center, Oklahoma City, OK

${ }^{2}$ Consultant, Granite Bay, CA

${ }^{3}$ Florida Hospital, Tampa, FL

${ }^{4}$ Health Priorities, Cape Girardeau, MO

${ }^{5}$ Montana Diabetes Program, Lewistown, MT

${ }^{6}$ American Diabetes Association, Arlington, VA

${ }^{7}$ Consultant, Albuquerque, NM

${ }^{8}$ University of Northern Colorado, Fort Collins, $\mathrm{CO}$

'University of Chicago, Chicago, IL

${ }^{10}$ San Diego City College, San Diego, CA

${ }^{11}$ American Association of Diabetes

Educators, Chicago, IL

${ }^{12}$ HealthPartners, Minneapolis, MN

${ }^{13}$ WellDoc, Columbia, MD

${ }^{14} \mathrm{~J}$ oslin Diabetes Center, Boston, MA

${ }^{15}$ National Certification Board for Diabetes Educators, Arlington Heights, IL

${ }^{16}$ Endocrinology Associates, Houston, TX

${ }^{17}$ Creative Pharmacists, Evans, GA

${ }^{18}$ Livongo, Mountain View, CA

${ }^{19}$ TMF Health Quality Institute, Austin, TX

${ }^{20} \mathrm{Glytec}$, Abingdon, VA

${ }^{21}$ University of Pittsburgh Diabetes Institute, Pittsburgh, PA

${ }^{22}$ The University of Texas Health Science Center at Houston, Houston, TX

Corresponding author: Leslie E. Kolb, Ikolb@aadenet.org.

https://doi.org/10.2337/ds17-0067

(C)2017 by the American Diabetes Association. Readers may use this article as long as the work is properly cited, the use is educational and not for profit, and the work is not altered. See http:ll creativecommons.org/licenses/by-nc-nd/3.0 for details.

This article was copublished in Diabetes Care 2017;40:1409-1419 and The Diabetes Educator 2017;43:449-464 and is reprinted with permission. The previous version of this article, also copublished in Diabetes Care and The Diabetes Educator, can be found at Diabetes Care 2012;35:2393-2401 (https://doi.org/10.2337/dc12-1707).

$y$ the most recent estimates, 30.3 million people in the U.S. have diabetes. An estimated 23.1 million have been diagnosed with diabetes and 7.2 million are believed to be living with undiagnosed diabetes. At the same time, 84.1 million people are at increased risk for type 2 diabetes. Thus, more than 114 million Americans are at risk for developing the devastating complications of diabetes (1).

Diabetes self-management education and support (DSMES) is a critical element of care for all people with diabetes. DSMES is the ongoing process of facilitating the knowledge, skills, and ability necessary for diabetes self-care, as well as activities that assist a person in implementing and sustaining the behaviors needed to manage his or her condition on an ongoing basis, beyond or outside of formal self-management training. In previous National Standards for Diabetes Self-Management Education and Support (Standards), DSMS and DSME were defined separately, but these Standards aim to reflect the value of ongoing support and multiple services.

The Standards define timely, evidence-based, quality DSMES services that meet or exceed the Medicare diabetes self-management training (DSMT) regulations, however, these Standards do not guarantee reimbursement. These Standards provide evidence for all diabetes self-management education providers including those that do not plan to seek reimbursement for DSMES. The current Standards' evidence clearly identifies the need to provide person-centered services that embrace the ever-increasing technological engagement platforms and systems. The hope is that payers will view these Standards as a tool for reviewing DSMES reimbursement requirements and consider change to align with the way their beneficiaries' engagement preferences have evolved. Research confirms that less than $5 \%$ of Medicare beneficiaries utilize their DSMES benefits $(2,3)$. Changes in reimbursement policies stand to increase DSMES access and utilization, which will result in positive impact to beneficiaries' clinical outcomes, quality of life, health care utilization, and costs (4).

It is necessary to learn how to manage diabetes and prevent or delay the complications $(5,6)$. The Standards are designed to define 
quality DSMES and assist those who provide DSMES services to implement evidence-based DSMES. Numerous studies have shown the benefits of DSMES, which include improved clinical outcomes and quality of life while reducing hospitalizations and health care costs (2,7-12). Four critical time points for providing DSMES - at diagnosis, annually, when complicating factors occur, and during transitions in care-have been documented and should be used to guide health care professionals' referrals (13). Engagement in DSMES services improves hemoglobin A1C (A1C) by $0.6 \%$, as much as many medications, with no side effects (8). However, greater A1C improvement was associated with DSMES services greater than $10 \mathrm{~h}(8,11)$.

The Standards are applicable to educators in solo practice as well as those in large multicenter programs (14), care coordination programs, population health programs, and technology-enabled models of care $(15,16)$. By following the Standards, DSMES should be incorporated in new and emerging models of care, including virtual visits, Accountable Care Organizations, Patient-Centered Medical Homes, population health programs, and value-based payment models (17-20). The Standards do not endorse any one approach, but rather seek to delineate the commonalities among effective and evidence-based DSMES strategies. These Standards are used in the field for recognition by the American Diabetes Association (ADA) and accreditation by the American Association of Diabetes Educators (AADE). They also serve as a guide for nonaccredited and nonrecognized providers of diabetes education.

Many DSMES services encounter people who are diagnosed with prediabetes. It is important to note that DSMES and the National Diabetes Prevention Program (National DPP) lifestyle change program are tailored for different audiences with different needs and different desired outcomes. The Centers for Disease Control and Prevention's (CDC) Diabetes Prevention Recognition Program assures that organizations can deliver the lifestyle change program effectively and achieve the outcomes necessary to prevent or delay onset of type 2 diabetes. To achieve CDC recognition, organizations must use a CDC-approved curriculum and meet national quality standards designed specifically for type 2 diabetes prevention programs. Those who deliver DSMES programs are well positioned to also offer the National DPP lifestyle change program, but they should meet the standards for the National DPP (21). The National DPP and DSMES co-located within organizations have been found to be successful and the outcome of this partnership allows for the sharing of expertise and the easy transition from one service to another (22).

This revision of the Standards highlights the focus of the individual with diabetes as the center of their care team, recognizing that a person with diabetes visits their primary care provider (PCP) four times per year on average, and the average PCP appointment is $18-20$ min (23). This equates to the person with diabetes spending less than $1 \%$ of their life with their health care team accessing services (23). Thus, the focus of the Standards should include helping the person with diabetes develop problem-solving skills and attain ongoing decision-making support necessary to self-manage diabetes. In addition, encouraging e-health tools (24) and online peer support (25) will allow for the implementation of a complete feedback loop essential to facilitate ongoing self-management $(16,26)$. Diabetes also carries with it a risk for burnout, which, as it develops, can lead to poorer health outcomes (27). Health care teams must consider the burden of treatment placed upon those living with diabetes - in essence, the "work of being a patient"—and consider all decisions within the lens of the individual's capacity (28). All DSMES services must focus on the priorities, concerns, and preferred delivery method and timing of the individual incorporating a person-centered approach. The minimally disruptive model of care defines a goal of maximizing participant outcomes with the minimal amount of work required by the person with diabetes to help simplify diabetes management and not add complexity (29).

Previous Standards have used the term program; however, when focusing on the needs of an individual, this term is no longer relevant. The use of DSMES services more clearly delineates the need to individualize and identify the elements of DSMES appropriate for an individual. This revision encourages providers of DSMES to embrace a contemporary view of the new complexities of the evolving health care landscape $(13,30)$.

Because of the dynamic nature of health care and diabetes-related research, the Standards have previously been reviewed and revised approximately every five years by key stake-holders and experts within the diabetes care and education community. In 2016, the Task Force was jointly convened by AADE and ADA. Members of the Task Force included experts from numerous health care professional disciplines and individuals with diabetes. Representatives from public health; those practicing with underserved populations including rural primary care and other rural health services; virtual, pharmacy, insurer programs; individual practices and large urban specialty practices; and urban hospitals served on the Task Force. The Task Force was charged with reviewing the current National Standards for DSMES for appropriateness, relevance, and scientific basis, and updating them based on the available evidence and expert consensus. Given the rapidly changing health care environment and the ever-growing field of technology, the 2017 Standards Revision 
Task Force recognizes the potential need to review the literature for evidence-driven updates more frequently in the future as advances in health care delivery are evolving.

\section{STANDARD 1}

\section{Internal Structure}

The provider(s) of DSMES services will define and document a mission statement and goals. The DSMES services are incorporated within the organization-large, small, or independently operated.

Documentation of a defined structure, mission, and goals supports effective provision of DSMES. Mission defines the core purpose of the organization and assists in developing professional practice and services. Business literature, case studies, and reports of successful organizations emphasize the importance of clear and shared missions, goals, and defined relationships $(31,32)$. The absence of these common goals and relationships is cited as one barrier to success (32). Defined leadership is needed to remove any servicerelated obstacles and find resources to advance DSMES services (33). Therefore, entities providing DSMES services must develop lines of communication and support to be clear on their mission, outcomes, and quality improvement measurement (34). The Chronic Care Model supports the need for documented organizational mission and goals (33).

According to The Joint Commission, documentation of an organization's structure is equally important for both small and large health care organizations (35). Providers of DSMES working within a larger organization will have the organization document recognition of and support of quality DSMES as an integral component to their mission (35). For smaller or independent providers of DSMES, they will identify and document their own appropriate mission, goals, and structure to fit the function in the communities they serve (34).

\section{STANDARD 2}

\section{Stakeholder Input}

The provider(s) of DSMES services will seek ongoing input from valued stakeholders and experts to promote quality and enhance participant utilization.

The purpose of seeking stakeholder input in the ongoing planning process is to gather information and foster ideas that will improve the utilization, quality, measurable outcomes, and sustainability of the DSMES services. Stakeholders can be identified from DSMES participants, referring practitioners, and community-based groups that support DSMES (e.g., health clubs and health care professionals [both within and outside of the organization]) who provide input to promote value, quality, access, and increased utilization $(36,37)$. Social determinants related to the population served will be used to guide stakeholder selection and facilitate the connection between the DSMES services, the participant population, the health care providers, and the community $(38,39)$.

A planned, documented strategy to engage and elicit input from stakeholders will shape how DSMES is developed, utilized, monitored, and evaluated $(33,37,40,41)$. If the provider of DSMES is experiencing a lack of referrals or low utilization, the stakeholders can assist with the solution $(42,43)$. The goal is to provide effective and dynamic DSMES services that are person-centered, culturally relevant, and responsive to the referring practitioner and participant-identified needs (38), ultimately engaging participants in lifelong learning $(13,41)$.

\section{STANDARD 3}

\section{Evaluation of Population Served}

The provider(s) of DSMES services will evaluate the communities they serve to determine the resources, design, and delivery methods that will align with the population's need for DSMES services.

Currently, the majority of people with and at risk for diabetes do not receive DSMES $(2,3,10,44,45)$. While there are many barriers to DSMES, one crucial issue is access (46-48). Providers of DSMES, after clarifying the specific populations they are able to serve, must understand their community and regional demographics $(47,49-53)$.

Individuals, their families, and communities require education and support options and tools that align with their needs (54-56). The provider(s) of DSMES must ensure the necessary educational alternatives are available $(40,54)$. Understanding the population's demographic characteristics, including ethnic/cultural background, sex, age, levels of formal education, literacy, and numeracy (57-60) as well as perception of diabetes risk and associated complications is necessary (45).

It is essential to identify the barriers that prevent access to DSMES during the assessment process (61-63). Individuals' barriers may include socioeconomic or cultural factors, participant schedules, health insurance shortfalls, perceived lack of need, and limited encouragement from other health care practitioners to engage in DSMES $(15,64-68)$.

Models that include population health and disease management, an interprofessional team, and ongoing social support improve both practice and individual outcomes $(40,69,70)$. Medical management integrated with DSMES improves access, clinical outcomes, and cost-effectiveness $(71,72)$. Creative solutions incorporating technology to increase reach and engagement must be examined $(73,74)$. Telehealth, electronic health records (EHR), mobile applications, and cognitive computing will proactively identify and track participants while offering endless opportunities 
for individualized and contextualized DSMES (16,75-78).

\section{STANDARD 4}

\section{Quality Coordinator Overseeing DSMES Services}

A quality coordinator will be designated to ensure implementation of the Standards and oversee the DSMES services. The quality coordinator is responsible for all components of DSMES, including evidencebased practice, service design, evaluation, and continuous quality improvement.

Ensuring quality is an essential component of the chronic care model (33). Person-centered health care is associated with improved outcomes (79-81) and better relationships between referring practitioners, individuals, and teams $(82,83)$. For DSMES services to be sustainable, quality must be a priority $(84,85)$.

Previous versions of the Standards used the term program coordinator; however, with new models of care and payment methods evolving, DSMES services need to demonstrate how these services affect overall participant outcomes. The change to quality coordinator reflects the need to address quality within all levels of DSMES services offered, concurrent with implementation. Most importantly, the quality coordinator is charged with collecting and evaluating data to identify gaps in DSMES, providing feedback on the performance of the DSMES services to team members, referring practitioners, and the organization's administration. The use of EHR and person-centric software improves care (86-92) and assists the quality coordinator in evaluating the effectiveness of DSMES. The quality coordinator utilizes data mining to inform payers and members of the health care team of the clinical outcomes of DSMES. Although the quality coordinator does not require additional degrees or certifications in informatics, developing an understanding of these skills-as well as marketing, health care administration, and business management-will be helpful as the health care environment evolves. The quality coordinator does need to understand the process of identifying, analyzing, and communicating quality data. In large health systems, the quality coordinator may partner with other team members to support quality improvement. In most DSMES entities the quality coordinator will manage the overall services and may be part of the instructional team.

\section{STANDARD 5}

\section{DSMES Team}

At least one of the team members responsible for facilitating DSMES services will be a registered nurse, registered dietitian nutritionist, or pharmacist with training and experience pertinent to DSMES, or be another health care professional holding certification as a diabetes educator (CDE) or Board Certification in Advanced Diabetes Management (BC-ADM). Other bealth care workers or diabetes paraprofessionals may contribute to DSMES services with appropriate training in DSMES and with supervision and support by at least one of the team members listed above.

The evidence supports an interprofessional team approach to diabetes care, education, and support (93). Current research continues to support nurses, dietitians, and pharmacists as providers of DSMES responsible for curriculum development $(13,14,94-98)$. Expert consensus supports the need for specialized clinical knowledge in diabetes and behavior change principles for DSMES team members (99). Certification as a CDE (National Certification Board for Diabetes Educators [NCBDE] $)(86,100)$ or BC-ADM (AADE) $(86,101)$ demonstrates specialized training beyond basic discipline preparation and mastery of a specific body of knowledge. All DSMES team members must document appropriate continuing educa- tion of diabetes-related content, ensuring their continuing competence in their respective roles.

Registered nurses, registered dietitian nutritionists, pharmacists, and members of health care disciplines that hold a certification as a CDE or BC-ADM can perform all the DSMES services including clinical assessments (14,100-102). Paraprofessionals with additional training in DSMES effectively contribute to the DSMES team. Diabetes paraprofessionals (e.g., medical assistants, community health workers, peer educators, etc.) can instruct, reinforce self-management skills, support behavior change, facilitate group discussion, and provide psychosocial support and ongoing self-management support (102). Paraprofessionals must receive continuing education specific to the role they serve within the team and must directly report to the quality coordinator or one of the qualified DSMES team members $(14,71,99,102-106)$. For services outside the expertise or scope of the DSMES provider, a mechanism must be in place to ensure that the participant is given the information needed to be referred to the appropriate health care professionals $(99,107)$.

\section{STANDARD 6}

\section{Curriculum}

A curriculum reflecting current evidence and practice guidelines, with criteria for evaluating outcomes, will serve as the framework for the provision of DSMES. The needs of the individual participant will determine which elements of the curriculum are required.

Individuals with diabetes, and those supporting them, have much to learn to enable effective self-management. DSMES provides this education in an up-to-date, evidence-based, and flexible curriculum $(108,109)$. The options for delivery of the curriculum have grown dramatically as technology has been incorporated into health care.

The curriculum is the evidencebased foundation from which the 
appropriate content is drawn to build an individualized education plan based on each participant's concerns and needs. The curriculum content must be supplemented with appropriate resources and supporting education materials. A curriculum also specifies effective teaching strategies and methods for evaluating learning outcomes $(5,110,111)$. The curriculum must be dynamic (5,97,111-113). Recent education research endorses the inclusion of practical problem-solving approaches and collaborative care, addressing psychosocial issues, behavior change, and strategies to sustain self-management efforts (40,114-120).

The following core content areas, including the AADE7 Self-Care Behaviors, demonstrate successful outcomes $(13,109,121,122)$ and must be reviewed to determine which are applicable to the participant:

- Diabetes pathophysiology and treatment options

- Healthy eating

- Physical activity

- Medication usage

- Monitoring and using patientgenerated health data (PGHD)

- Preventing, detecting, and treating acute and chronic complications

- Healthy coping with psychosocial issues and concerns

- Problem solving

The content areas listed, as well as educating the participant on navigating the health care system, learning self-advocacy, and e-health education $(24,105,106,115-117)$, can be adapted for all practice settings and provide a solid outline and agenda for a DSMES curriculum. It is crucial that the content be tailored to match individuals' needs and be adapted as necessary for age, developmental stage, type of diabetes, cultural factors, health literacy and numeracy, and comorbidities (123-127).

\section{STANDARD 7}

\section{Individualization}

The DSMES needs will be identified and led by the participant with assessment and support by one or more DSMES team members. Together, the participant and DSMES team member(s) will develop an individualized DSMES plan.

People with diabetes should engage in DSMES during various stages after their diabetes diagnosis $(5,13)$. Regardless of the stage, people with diabetes have their own priorities and needs. The DSMES services must be designed using personcentered care practices, in collaboration with the participant, focusing on the participant's priorities and values $(5,13,128)$. The most important element to appreciate is that no participant is required to complete a set DSMES structure. When participants have achieved their goals, they can determine that their initial DSMES intervention is complete. However, DSMES is an ongoing, lifelong process, with ongoing assessments of AADE7 Self-Care Behaviors (122) and continual support $(5,13)$.

Research indicates the importance of individualizing DSMES to each participant $(129,130)$. The assessment process is collaboratively conducted by a health care professional with the participant to identify needs and potential self-management support strategies. The health care professional uses the information gleaned on assessment to determine the appropriate educational and behavioral interventions, including enhancing the participant's problem-solving skills $(8,11,130)$. The assessment must incorporate information about the individual's medical history, age, cultural influences, health beliefs and attitudes, diabetes knowledge, diabetes self-management skills and behaviors, emotional response to diabetes, disease burden, ability, readiness to learn, literacy level (including health literacy and numeracy), phys- ical limitations, family support, peer support (in person or via social networking sites), financial status, and other barriers (29,131-134). After the initial assessment, additional assessments can be incremental over time as indicated based on participant need (13).

The DSMES team member(s) will use clear health communication principles, using plain language, avoiding jargon, making information culturally relevant, using language- and literacy-appropriate education materials, and using interpreter services when indicated (135). Evidence-based communication strategies such as collaborative goal setting, action planning, motivational interviewing, shared decision making, cognitive behavioral therapy, problem solving, self-efficacy enhancement, teach-back, and relapse-prevention strategies are also effective $(120,136-139)$. It is crucial to develop action-oriented behavior change goals and objectives $(130,140)$. Creative, person-centered, experience-based delivery methods beyond the mere acquisition of knowledge are effective for supporting informed decision making and meaningful behavior change and addressing psychosocial concerns $(122,141)$. Moving beyond static lecture methodology, incorporating meaningful discussions to address individual needs, and using interactive teaching styles are required. Incorporating PGHD, especially blood glucose and/or continuous glucose monitoring data, into decision making individualizes self-management and empowers participants to fully engage in personal problem solving to change behavior and improve outcomes (16,142-144). There is strong evidence that incorporating text messaging into DSMES interventions improves engagement and outcomes $(25,145-147)$. Use of digital technology (cloud-based, telehealth, data management platforms, apps, and social media) enhances the ability to employ a technologyenabled self-management feedback 
loop with four key elements: two-way communication, analysis of PGHD, customized education, and individualized feedback to provide real-time engagement in self-management, as well as to enable and empower participants (16).

Reassessment during key times, such as when complicating factors influence self-management and during transitions of care, can determine whether there is need for additional or different DSMES services $(13,148)$. A variety of assessment modalities, including online assessments via consumer portals and EHR, tablet computers that integrate with EHR, text messaging, web-based tools, automated telephone follow-up, and remote monitoring tools can be used (77,149-152). Selecting validated tools, used for assessment and ongoing evaluation, will generate more evidence to support DSMES (153). Although not an exhaustive list or applicable to all populations, examples of assessment tools can be found in the Standards' glossary (Table 1).

The assessment and education plan, intervention, and outcomes will be documented in the participant's health record. Documentation of participant contact with DSMES team members will guide the education process, provide evidence of communication among other members of the individual's health care team, and demonstrate adherence to guidelines, all of which will assist in long-term management of diabetes care and diabetes self-management support (86). Using technology tools will increase access to information for all team members to work collaboratively and have access to documentation.

\section{STANDARD 8}

\section{Ongoing Support}

The participant will be made aware of options and resources available for ongoing support of their initial education, and will select the option(s) that will best maintain their self-management needs.
While initial DSMES is necessary, it is not sufficient for participants to sustain a lifetime of diabetes self-management $(13,115)$. Initial improvements in metabolic and other outcomes have been shown to diminish after six months $(13,115)$. To maintain behavior at the level needed to effectively self-manage diabetes, participants with type 1 diabetes (12) and type 2 diabetes (11) need ongoing diabetes self-management support. Ongoing support is defined as resources which help the participant implement and sustain the ongoing skills, knowledge, and behavior changes needed to manage their condition (13). The vital point is that the participant selects the resource or activity that best suits their selfmanagement needs.

A variety of strategies are available for engaging in ongoing support both within and outside DSMES services. Support can include internal or external group meetings (connection to community and peer groups [online or locally]), ongoing medication management, continuing education, resources to support new or adjustments to existing behavior change goal-setting, physical activity programs, weightloss support, smoking cessation, and psychosocial support among others (154-159). Connecting the participant to existing community resources outside of the DSMES entity is more realistic for smaller organizations.

The effectiveness of providing support through diabetes educators, disease-management programs, trained peers, diabetes paraprofessionals, community-based programs, or through the use of technology (text, e-mail, social media, web-based, mobile, digital, and wearable and wireless devices) has also been established (154-156,160-165). Peer support using social networking sites improves glucose management, especially in people with type 2 diabetes (25). Practitioners can highlight the benefits and accessibility of online diabetes communities as a resource to help participants learn from others living with the condition, facing similar issues, available $24 \mathrm{~h}$ a day, seven days a week, when it is convenient for them to engage. A personcentered approach is recommended to incorporate ongoing support plans in clinical care $(115,128,166)$.

\section{STANDARD 9}

\section{Participant Progress}

The provider(s) of DSMES services will monitor and communicate whether participants are achieving their personal diabetes self-management goals and other outcome(s) to evaluate the effectiveness of the educational intervention(s), using appropriate measurement techniques.

Effective DSMES is a significant contributor to long-term, positive health outcomes and clinical improvement (8). Assessing needs and communicating information and skills that promote effective coping and selfmanagement must involve a personalized and comprehensive approach (13). The provider(s) of DSMES will rely on behavior change goal-setting strategies to help participants meet their personal targets (167). There are proven steps based on goal-setting theory that improve outcomes. The role of the DSMES team is to aid the goal-setting process and adjust based on participant needs and circumstances $(168,169)$. Validly measuring the achievement of SMART goals (specific, measurable, achievable, realistic, and time-bound) and action planning including an assessment of confidence and conviction is essential $(170,171)$.

To demonstrate the benefits of DSMES, it is important for DSMES providers to track relevant evidencebased DSMES outcomes such as knowledge, behavior, clinical, quality of life, cost-savings, and satisfaction outcomes. The AADE Outcome Standards for Diabetes Education specify behavior change as the key outcome and the AADE7 Self-Care Behaviors (healthy eating, being active, taking medication, monitoring, problem solving, reducing risk, and healthy coping) provide a useful frame- 


\section{TABLE 1. Glossary of Terms}

Assessment. A process to gather the information necessary to make a diabetes self-management education and support (DSMES) plan with the participant. The DSMES assessment must be completed by a health care professional.

\section{Assessment Tools.}

- The Diabetes Distress Scale (DDS) (short form)

- A two-question initial screening tool to assess diabetes-specific distress (followed by the full 17-item scale when indicated) (175)

- The WHO (Five) Well-Being Index

- Validated in many languages, is a reliable measure of emotional functioning and screen for depression and has been used extensively in research and clinical care (176), including the DAWN2 study (Diabetes Attitudes, Wishes and Needs 2) (177)

- Problem Areas in Diabetes (PAID) scale

- A 20-item measure of diabetes-specific distress identifying emotional distress and burden associated with diabetes (178) (pediatric and teen versions $[179,180]$ are also available)

- Diabetes Self-Efficacy Scale

- An eight-item self-report scale designed to assess confidence in performing diabetes self-care activities (181)

- Self-Care Inventory-Revised (SCl-R)

- A survey that measures what people with diabetes do versus what they are advised to do in their diabetes treatment plan (182)

- Summary of Diabetes Self-Care Activities (SDSCA)

o An 11-item or expanded 25-item measure of diabetes self-care behaviors (183)

- Starting The Conversation (STC)

- An eight-item simplified food frequency instrument designed for use in primary care and health-promotion settings (184)

- Three-item screen

- A tool to measure health literacy. It asks how often someone needs help reading hospital materials, how confident they are filling out forms, and how often they have difficulty understanding their medical condition (185)

Behavioral goal setting. The practice of identifying health behaviors to modify, setting a target to reach, and planning a course to achieve the target.

Capacity. The ability a person has to understand and manage their condition.

Cognitive computing. The simulation of human thought processes in a computerized model to mimic the way the human brain works.

Data mining. The ability of a coordinator to aggregate data from within their organization's documentation system.

Diabetes paraprofessional. A person with a nonmedical background who can provide support as a part of a diabetes care team.

Diabetes professional. A person with a medical background who is part of a diabetes care team.

Diabetes self-management education and support (DSMES). The ongoing process of facilitating the knowledge, skills, and ability necessary for prediabetes and diabetes self-care, and the activities that assist the person with diabetes or prediabetes in implementing and sustaining the behaviors needed to manage his or her condition on an ongoing basis beyond or outside of formal self-management training. This process incorporates the needs, goals, and life experiences of the person with diabetes or prediabetes and is guided by evidence-based standards. Support (whether behavioral, educational, psychosocial, or clinical) helps implement informed decision making, self-care behaviors, problem solving, and active collaboration with the health care team and to improve clinical outcomes, health status, and quality of life.

Disease burden. The impact a disease has on the various components of a participant's life, such as physical, financial, or mental aspects.

Electronic health records (EHR). The digital version of a patient's chart. EHR are available in real time and available to patients and their care team immediately.

Goals. The desired results for DSMES, set by those receiving DSMES services and their care teams. 
TABLE 1. Glossary of Terms, continued from p. 307

Health care stakeholder. Anyone involved in or affected by the financing, implementation, or outcome of a service, practice, process, or decision made by another (e.g., healthcare, health policy). Examples of stakeholders with interest in health care are providers, patients (health care consumers), payers, etc.

Mission. Core purpose, direction, and why the organization exists. It describes who it serves and how it does it.

National Diabetes Prevention Program (National DPP). An evidence-based intervention that allows purchasers, payers, and providers to prevent or delay onset of type 2 diabetes in patients with prediabetes or at high risk for type 2 diabetes. The intervention is founded on the science of the Diabetes Prevention Program research study and several translation studies. These studies showed that making modest behavior changes helped participants lose 5 to $7 \%$ of their body weight and reduced the risk of developing type 2 diabetes by $58 \%$ in adults with prediabetes (71\% for people over 60 years of age). The National DPP lifestyle change program is a year-long structured program (in-person group, online, or combination) consisting of:

- an initial six-month phase offering at least 16 sessions over 16-24 weeks and a second six-month phase offering at least one session a month (at least six sessions)

- facilitation by a trained lifestyle coach

- use of a CDC-approved curriculum

- regular opportunities for direct interaction between the lifestyle coach and participants

- focus on behavior modification, managing stress, and peer support

The CDC Diabetes Prevention Recognition Program assures that organizations can deliver the lifestyle change program effectively and achieve the outcomes necessary to prevent or delay the onset of type 2 diabetes. To achieve CDC recognition, organizations must use a CDC-approved curriculum and meet national quality standards.

Patient-generated health data (PGHD). Information gathered by patients or health care professionals from diabetes technology or devices (e.g., diabetes software, diabetes glucose monitors, etc.).

Person-centered care practice. Efforts to recognize the people using health services as equal members of the care team in planning, executing, and monitoring their care and keeping their needs at the forefront.

Prediabetes. Blood glucose levels that are higher than normal but not high enough to be diagnosed as diabetes.

Service. A system or actions dedicated to supplying a demand.

Social determinants. The conditions in which someone lives, learns, works, and ages that affect their health.

work for assessment, documentation, and evaluation $(111,122)$. Providers of DSMES should select validated measurement tools to accurately track outcomes.

Tracking and communication of individual outcomes must occur at appropriate intervals, e.g., before and after engaging in DSMES. The interval depends on the nature of the outcome itself (e.g., A1C every three to six months) and the time frame specified based on the individual's personal goals. For some areas, the indicators, measures, and time frames will be based on guidelines from professional organizations or government agencies (8).

STANDARD 10

Quality Improvement

The DSMES services quality coordinator will measure the impact and effectiveness of the DSMES services and identify areas for improvement by conducting a systematic evaluation of process and outcome data.

Formal quality improvement strategies can lead to improved diabetes outcomes $(84,85)$. DSMES must be responsive to advances in knowledge, treatment strategies, education strategies, and psychosocial interventions, as well as consumer trends and the changing health care environment. By measuring and monitoring both process and outcome data on an ongoing basis, providers of DSMES can identify areas of improvement and adjust participant engagement strategies and service offerings accordingly. Evaluation can contribute to the sustainability of the service. Positive results from quality initiatives can be used in marketing efforts and shared with administration in larger health systems. A focus on quality is also part of overall medical quality initia- tives including pay-for-performance and the Medicare Access and CHIP Reauthorization Act (MACRA), which has shifted provider payment based on productivity to one that focuses on quality and outcomes (172).

The Institute for Healthcare Improvement suggests three fundamental questions that should be answered by an improvement process: What are we trying to accomplish? How will we know a change is an improvement? And what changes can we make that will result in an improvement (173)?

Once areas for improvement are identified, the DSMES quality coordinator determines time lines and important milestones, including data collection, analysis, and presentation of results. Measuring a variety of outcomes ensures that change is successful without causing additional problems in the system. Outcome 
measures indicate the result of a process (i.e., whether changes are leading to improvement, e.g., a change in a behavior or a biomarker [A1C]), while process measures provide information about what caused those results (e.g., if the participant attended DSMES sessions or had an exam done) (173). Process measures are often targeted to those processes that affect the most important outcomes. Measures generally recommended for DSMES services include behavioral measures (e.g., participant's report of self-management activities and psychosocial behaviors including distress), clinical measures (e.g., changes in weight or $\mathrm{A} 1 \mathrm{C}$ ), operational measures (e.g., participant satisfaction, financial indicators, no-show rates, or results of marketing efforts), and process measures (e.g., participants receiving services, referral to DSMES, or referral for an eye exam). A variety of methods can be used for quality improvement initiatives, such as the Plan-Do-Study-Act model, Six Sigma, Lean, Re-AIM, and workflow mapping. There are resources available to assist those initiating quality improvement programs for the first time or for those looking for new options $(84,85,172,174)$.

\section{Acknowledgments}

The authors thank Lindsey Wahowiak, Washington, DC, for her editorial assistance in preparing this manuscript.

\section{References}

1. Centers for Disease Control and Prevention. National Diabetes Statistics Report, 2017: Estimates of Diabetes and Its Burden in the United States [Internet]. Atlanta: Centers for Disease Control and Prevention; 2017. Available from https:// www.cdc.gov/diabetes/pdfs/data/statistics/ national-diabetes-statistics-report.pdf. Accessed 26 July 2017

2. Strawbridge LM, Lloyd JT, Meadow A, Riley GF, Howell BL. One-year outcomes of diabetes self-management training among Medicare beneficiaries newly diagnosed with diabetes. Med Care 2017;55:391-397

3. Strawbridge LM, Lloyd JT, Meadow A, Riley GF, Howell BL. Use of Medicare's diabetes self-management training benefit. Health Educ Behav 2015;42:530-538

4. Center for Health Law and Policy Innovation of Harvard Law School. Reconsidering cost-sharing for diabetes self-management education: recommendation for policy reform [Internet], 2015. Available from https://www.diabetes educator.org/docs/default-source/ advocacy/reconsidering-cost-sharingfor-dsme-chlpi-paths-6-11-2015-(finaldraf.pdf?sfvrsn=2. Accessed 3 June 2017

5. American Diabetes Association. Lifestyle management. Sec 4 In Standards of Medical Care in Diabetes - 2017. Diabetes Care 2017;40(Suppl.1):S33-S43

6. Knowler WC, Fowler SE, Hamman RF, et al.; Diabetes Prevention Program Research Group. 10-year follow-up of diabetes incidence and weight loss in the Diabetes Prevention Program Outcomes Study. Lancet 2009;374:1677-1686

7. He X, Li J, Wang B, et al. Diabetes self-management education reduces risk of all-cause mortality in type 2 diabetes patients: a systematic review and metaanalysis. Endocrine 2017;55: 712-731

8. Chrvala CA, Sherr D, Lipman RD. Diabetes self-management education for adults with type 2 diabetes mellitus: a systematic review of the effect on glycemic control. Patient Educ Couns 2016;99: 926-943

9. Cooke D, Bond R, Lawton J, et al.; U.K. NIHR DAFNE Study Group. Structured type 1 diabetes education delivered within routine care: impact on glycemic control and diabetes-specific quality of life. Diabetes Care 2013;36:270-272

10. Duncan I, Ahmed T, Li QE, et al. Assessing the value of the diabetes educator. Diabetes Educ 2011;37:638-657

11. Pillay J, Armstrong MJ, Butalia S, et al. Behavioral programs for type 2 diabetes mellitus. Ann Intern Med 2015;163:848-860

12. Pillay J, Armstrong MJ, Butalia S, et al. Behavioral programs for type 1 diabetes mellitus. Ann Intern Med 2015;163:836-847

13. Powers MA, Bardsley J, Cypress M, et al. Diabetes self-management education and support in type 2 diabetes: a joint position statement of the American Diabetes Association, the American Association of Diabetes Educators, and the Academy of Nutrition and Dietetics. Diabetes Educ 2015;41:417-430

14. American Association of Diabetes Educators. Competencies for diabetes educators and diabetes paraprofessionals [Internet], 2016. Available from https://www. diabeteseducator.org/docs/default-source/ practice/practice-resources/comp003.pdf. Accessed 23 May 2017

15. Kitsiou S, Paré G, Jaana M, Gerber B. Effectiveness of mHealth interventions for patients with diabetes: an overview of systematic reviews. PLoS One 2017;12:e0173160
16. Greenwood DA, Gee PM, Fatkin KJ, Peeples M. A systematic review of reviews evaluating technology-enabled diabetes self-management education and support. J Diabetes Sci Technol 2017;193229681771350: 1932296817713506

17. Knox L, Brach C, Schaefer J. Primary care practice facilitation curriculum (module 32). Rockville, MD: Agency for Healthcare Research and Quality [Internet] 2015. Available from https://pcmh.ahrq.gov/ sites/default/files/attachments/pcpf-module32-self-management-support.pdf. AHRQ Publication No. 15-0060-EF. Accessed 21 April 2017

18. Beebe C, Schmitt S. Engaging patients in education for self-management in an accountable care environment. Clin Diabetes 2011;29:123-126

19. Grady PA, Gough LL. Self-management: a comprehensive approach to management of chronic conditions. Am J Public Health 2014;104: e25-e31

20. National Institute of Diabetes and Digestive and Kidney Diseases. Changing landscape: from fee-forservice to value-based reimbursement [Internet]. Available from https://www. niddk.nih.gov/health-information/ health-communication-programs/ndep/ health-care-professionals/ practicetransformation/why-transform/changinglandscape/Pages/default.aspx. Accessed 3 June 2017

21. Centers for Disease Control and Prevention. Centers for Disease Control and Prevention Diabetes Prevention Recognition Program: standards and operating procedures [Internet]. Atlanta, GA: Centers for Disease Control and Prevention; 2015. Available from https:// www.cdc.gov/diabetes/ prevention/pdf/ dprp-standards.pdf. Accessed 23 May 2017

22. DiBenedetto JC, Blum NM, O'Brian CA, Kolb LE, Lipman RD. Achievement of weight loss and other requirements of the Diabetes Prevention and Recognition Program: a National Diabetes Prevention Program network based on nationally certified diabetes self-management education programs. Diabetes Educ 2016;42:678-685

23. Chen LM, Farwell WR, Jha AK. Primary care visit duration and quality: does good care take longer? Arch Intern Med 2009;169:1866-1872

24. Gee PM, Greenwood DA, Paterniti DA, Ward D, Miller LM. The eHealth Enhanced Chronic Care Model: a theory derivation approach. J Med Internet Res 2015;17:e86

25. Toma T, Athanasiou T, Harling L, Darzi A, Ashrafian H. Online social networking services in the management of patients with diabetes mellitus: systematic review and meta-analysis of rand-omised controlled trials. Diabetes Res Clin Pract 2014;106:200-211

26. Ceriello A, Barkai L, Christiansen JS, et al. Diabetes as a case study of chronic disease management with a personalized 
approach: the role of a structured feedback loop. Diabetes Res Clin Pract 2012;98:5-10

27. Fisher L, Hessler D, Glasgow RE, et al. REDEEM: a pragmatic trial to reduce diabetes distress. Diabetes Care 2013;36:2551-2558

28. Tran VT, Barnes C, Montori VM, Falissard B, Ravaud P. Taxonomy of the burden of treatment: a multi-country webbased qualitative study of patients with chronic conditions. BMC Med 2015;13:115

29. May CR, Eton DT, Boehmer K, et al. Rethinking the patient: using Burden of Treatment Theory to understand the changing dynamics of illness. BMC Health Serv Res 2014;14:281

30. National Institute of Diabetes and Digestive and Kidney Diseases. Principle 10: provide patient-centered diabetes care [article online]. Rockville, MD, National Institutes of Health, 2017. Available from https://www.niddk.nih.gov/healthinformation/health-communicationprograms/ndep/health-care-professionals/ guiding-principles/principle-10-providepatient-centered-care/Pages/principle10-provide-patient-centered-care.aspx. Accessed 23 May 2017

31. Macleod L. Mission, vision, and values statements: the physician leader's role. Physician Lead-ersh J 2016; (Sept-Oct):25

32. Carlson G, Greeley H. Is the relationship between your hospital and your medical staff sustainable? J Healthc Manag 2010;55:158-173; discussion 173-174

33. Stellefson M, Dipnarine K, Stopka C. The chronic care model and diabetes management in US primary care settings: a systematic review. Prev Chronic Dis 2013;10:E26

34. Stallworth Williams L. The mission statement: a corporate reporting tool with a past, present, and future. IJBC 2008:45:94-119

35. The Joint Commission. Specifications manual for Joint Commission National Quality Measures [Internet]. Oakbrook Terrace, IL: The Joint Commission on Accreditation of Healthcare. Available from https://manual.jointcommission. org/releases/TJC2016B1/rsrc55/Manual/ TableOfContentsTJC/ TJC_v2016B1.pdf. Accessed 23 May 2017

36. Centers for Disease Control and Prevention. Community-clinical linkages for the prevention and control of chronic diseases: a practitioner's guide [Internet]. Atlanta, GA, Centers for Disease Control and Prevention, 2016. Available from https://www.cdc.gov/dhdsp/pubs/docs/ ccl-practitioners-guide.pdf. Accessed 23 May 2017

37. Institute for Credentialing Excellence. National Commission for Certifying Agencies Standards for the Accreditation of Certification Programs [Internet], 2004; revised 2014. Available from http://www. credentialingexcellence.org/p/pr/vi/ prodid $=169$. Accessed 23 May 2017

38. Lawn S, Battersby M, Lindner H, et al. What skills do primary health care professionals need to provide effective self-management support? Seeking consumer perspectives. Aust J Prim Health 2009; $15: 37$

39. Garg A, Boynton-Jarrett R, Dworkin $\mathrm{PH}$. Avoiding the unintended consequences of screening for social determinants of health. JAMA 2016; 316:813-814

40. Siminerio LM, Piatt GA, Emerson S, et al. Deploying the chronic care model to implement and sustain diabetes selfmanagement training programs. Diabetes Educ 2006;32:253-260

41. Bechtel C, Ness DL. If you build it, will they come? Designing truly patientcentered health care. Health Aff (Millwood) 2010;29:914-920

42. Centers for Disease Control and Prevention. A framework for program evaluation [Internet]. Atlanta, GA, Centers for Disease Control and Prevention, 2017. Available from https://www.cdc.gov/eval/ framework. Accessed 24 May 2017

43. Gallivan J, Greenberg R, Brown C. The National Diabetes Education Program evaluation framework: how to design an evaluation of a multifaceted public health education program [article online]. Prev Chronic Dis 2008;5:A134. Available from https://www.ncbi.nlm.nih.gov/pmc/articles/ PMC2578767/. Accessed 23 May 2017

44. Li R, Shrestha S, Lipman R, et al. Diabetes self-management education and training among privately insured persons with newly diagnosed diabetes - United States, 2011-2012 [article online]. Morb Mort Wkly Rep 2014;63:1045-1049 Available from https://www.cdc.gov/mmwr/preview/ mmwrhtml/mm6346a2.htm. Accessed 2 June 2017

45. Piccinino LJ, Devchand R, Gallivan J, Tuncer D, Nicols C, Siminerio LM. Insights from the National Diabetes Education Program National Diabetes Survey: opportunities for diabetes self-management education and support. Diabetes Spectr 2017;30: 95-100

46. Boren SA, Fitzner KA, Panhalkar PS, Specker JE. Costs and benefits associated with diabetes education: a review of the literature. Diabetes Educ 2009;35:72-96

47. Peyrot M, Rubin RR, Funnell MM, Siminerio LM. Access to diabetes selfmanagement education: results of national surveys of patients, educators, and physicians. Diabetes Educ 2009;35: 246-248, 252-256, 258-263

48. Rutledge SA, Masalovich S, Blacher RJ, Saunders MM. Diabetes self-management education programs in nonmetropolitan counties - United States, 2016. MMWR Surveill Summ 2017;66(SS-10):1-6

49. Sherr D, Lipman RD. The diabetes educator and the diabetes self-management education engagement. Diabetes Educ 2015;41:616-624

50. Cauch-Dudek K, Victor JC, Sigmond M, Shah BR. Disparities in attendance at diabetes self-management education programs after diagnosis in Ontario, Canada: a cohort study. BMC Public Health 2013;13:85

51. McWilliams JM, Meara E, Zaslavsky AM, Ayanian JZ. Health of previously uninsured adults after acquiring Medicare coverage. JAMA 2007; 298:2886-2894

52. Glasgow RE. Interactive media for diabetes self-management: issues in maximizing public health impact. Med Decis Making 2010;30:745-758

53. Curtis AB, Kothari C, Paul R, Connors E. Using GIS and secondary data to target diabetes-related public health efforts. Public Health Rep 2013;128: 212-220

54. Lorig K, Ritter PL, Villa FJ, Armas J. Community-based peer-led diabetes self-management: a randomized trial. Diabetes Educ 2009;35:641-651

55. Ricci-Cabello I, Ruiz-Pérez I, RojasGarcía A, Pastor G, Rodríguez-Barranco $\mathrm{M}$, Gonçalves DC. Characteristics and effectiveness of diabetes self-management educational programs targeted to racial/ ethnic minority groups: a systematic review, meta-analysis and meta-regression. BMC Endocr Disord 2014;14:60

56. Dorland K, Liddy C. A pragmatic comparison of two diabetes education programs in improving type 2 diabetes mellitus outcomes. BMC Res Notes 2014;7:186

57. Rosal MC, Ockene IS, Restrepo A, et al. Randomized trial of a literacysensitive, culturally tailored diabetes selfmanagement intervention for low-income Latinos: Latinos en control. Diabetes Care 2011;34:838-844

58. Mayer-Davis EJ, Beyer J, Bell RA, et al.; SEARCH for Diabetes in Youth Study Group. Diabetes in African American youth: prevalence, incidence, and clinical characteristics: the SEARCH for Diabetes in Youth Study. Diabetes Care 2009; 32(Suppl. 2):S112-S122

59. Liu LL, Yi JP, Beyer J, et al.; SEARCH for Diabetes in Youth Study Group. Type 1 and type 2 diabetes in Asian and Pacific islander U.S. youth: The SEARCH for Diabetes in Youth Study. Diabetes Care 2009;32(Suppl. 2):S133-S140

60. Hill-Briggs F, Batts-Turner M, Gary TL, et al. Training community health workers as diabetes educators for urban African Americans: value added using participatory methods. Prog Community Health Partnersh 2007:1:185-194

61. Unützer J, Schoenbaum M, Katon WJ, et al. Healthcare costs associated with depression in medically Ill fee-for-service Medicare participants. J Am Geriatr Soc 2009:57:506-510

62. Walker EA, Shmukler C, Ullman R, Blanco E, Scollan-Koliopoulus M, Cohen 
HW. Results of a successful telephonic intervention to improve diabetes control in urban adults: a randomized trial. Diabetes Care 2011;34:2-7

63. Wubben DP, Vivian EM. Effects of pharmacist outpatient interventions on adults with diabetes mellitus: a systematic review. Pharmacotherapy 2008;28:421-436

64. Madden J, Barnard A, Owen C. Utilisation of multidisciplinary services for diabetes care in the rural setting. Aust $\mathbf{J}$ Rural Health 2013;21:28-34

65. Remler DK, Teresi JA, Weinstock RS, et al. Health care utilization and self-care behaviors of Medicare beneficiaries with diabetes: comparison of national and ethnically diverse underserved populations. Popul Health Manag 2011;14:11-20

66. Peikes D, Chen A, Schore J, Brown R. Effects of care coordination on hospitalization, quality of care, and health care expenditures among Medicare beneficiaries: 15 randomized trials. JAMA 2009;301:603-618

67. Chomko ME, Odegard PS, Evert AB. Enhancing access to diabetes self-management education in primary care. Diabetes Educ 2016;42:635-645

68. Lorig K, Ritter PL, Turner RM, English $\mathrm{K}$, Laurent DD, Greenberg J. Benefits of diabetes self-management for health plan members: a 6-month translation study. J Med Internet Res 2016;18:e164

69. Piatt GA, Anderson RM, Brooks MM, et al. 3-year follow-up of clinical and behavioral improvements following a multifaceted diabetes care intervention: results of a randomized controlled trial. Diabetes Educ 2010;36:301-309

70. Clark CE, Smith LF, Taylor RS, Campbell JL. Nurse-led interventions used to improve control of high blood pressure in people with diabetes: a systematic review and meta-analysis. Diabet Med 2011;28:250-261

71. Gagliardino JJ, Arrechea V, Assad D, et al. Type 2 diabetes patients educated by other patients perform at least as well as patients trained by professionals. Diabetes Metab Res Rev 2013; 29:152-160

72. Siminerio L, Ruppert K, Emerson S, Solano F, Piatt G. Delivering diabetes self-management education (DSME) in primary care. Dis Manag Health Outcomes 2008;16:267-272

73. Hwee J, Cauch-Dudek K, Victor JC, Ng $\mathrm{R}$, Shah BR. Diabetes education through group classes leads to better care and outcomes than individual counselling in adults: a population-based cohort study. Can J Public Health 2014;105:e192-e197

74. Anzaldo-Campos MC, Contreras S, Vargas-Ojeda A, Menchaca-Díaz R, Fortmann A, Philis-Tsimikas A. Dulce wireless Tijuana: a randomized control trial evaluating the impact of Project Dulce and short-term mobile technology on glycemic control in a family medicine clinic in northern Mexico. Diabetes Technol Ther 2016;18:240-251

75. Stellefson M, Chaney B, Barry AE, et al. Web 2.0 chronic disease self-management for older adults: a systematic review. J Med Internet Res 2013;15:e35

76. Quinn CC, Shardell MD, Terrin ML, Barr EA, Ballew SH, Gruber-Baldini AL. Cluster-randomized trial of a mobile phone personalized behavioral intervention for blood glucose control. Diabetes Care 2011;34:1934-1942

77. Pereira K, Phillips B, Johnson C, Vorderstrasse A. Internet delivered diabetes self-management education: a review. Diabetes Technol Ther 2015;17:55-63

78. Siminerio L, Ruppert K, Huber K, Toledo FG. Telemedicine for Reach, Education, Access, and Treatment (TREAT): linking telemedicine with diabetes self-management education to improve care in rural communities. Diabetes Educ 2014; 40:797-805

79. Solorio R, Bansal A, Comstock B, Ulatowski K, Barker S. Impact of a chronic care coordinator intervention on diabetes quality of care in a community health center. Health Serv Res 2015;50:730-749

80. Bowers A, Owen R, Heller T. Care coordination experiences of people with disabilities enrolled in Medicaid managed care. Disabil Rehabil 2016;Aug 22:1-8

81. Gale RC, Kehoe D, Lit YZ, Asch SM, Kurella Tamura M. Effect of a dialysis access coordinator on preemptive access placement among veterans: a quality improvement initiative. Am J Nephrol 2017;45:14-21

82. Noël PH, Lanham HJ, Palmer RF, Leykum LK, Parchman ML. The importance of relational co-ordination and reciprocal learning for chronic illness care within primary care teams. Health Care Manage Rev 2013;38:20-28

83. MacPhail LH, Neuwirth EB, Bellows J. Coordination of diabetes care in four delivery models using an electronic health record. Med Care 2009;47:993-999

84. Tricco AC, Ivers NM, Grimshaw JM, et al. Effectiveness of quality improvement strategies on the management of diabetes: a systematic review and meta-analysis. Lancet 2012;379:2252-2261

85. Bodicoat DH, Mundet X, Davies MJ, et al.; GEDAPS Study Group. The impact of a programme to improve quality of care for people with type 2 diabetes on hard to reach groups: The GEDAPS study. Prim Care Diabetes 2015;9:211-218

86. Ngui D, Qiu MJ, Mann M. Targeting care gaps in patients with hypertension.

J Hypertens 2016; 34(Suppl. 1 - ISH 2016 Abstract Book):e247-e248

87. Camicia M, Chamberlain B, Finnie $\mathrm{RR}$, et al. White paper. The value of nursing care coordination: a white paper of the American Nurses Association. Nurs
Outlook 2013;61:490-501. Available from http://www.nursingworld.org/care coordinationwhitepaper. Accessed 23 May 2017

88. Cochrane J, Baus A. Developing interventions for overweight and obese children using electronic health records data [article online]. Online J Nurs Inform 2015;19 http://www.himss.org/ ResourceLibrary/GenResourceDetail.aspx? Item Number $=39758$. Accessed 23 May 2017

89. Herrin J, da Graca B, Aponte P, et al. Impact of an EHR-based diabetes management form on quality and outcomes of diabetes care in primary care practices. Am J Med Qual 2015;30:14-22

90. Benkert R, Dennehy P, White J, Hamilton A, Tanner C, Pohl JM. Diabetes and hypertension quality measurement in four safety-net sites: lessons learned after implementation of the same commercial electronic health record. Appl Clin Inform 2014;5:757-772

91. Orzano AJ, Strickland PO, Tallia AF, et al. Improving outcomes for high-risk diabetics using information systems. J Am Board Fam Med 2007; 20:245-251

92. Terry K. Mining EHR data for quality improvement [article online]. Med Econ 2015. Available from http:// medicaleconomics.modernmedicine.com/ medical-economics/news/mining-ehrdata-quality-improvement?page=full. Accessed 23 May 2017

93. Lau R, Stevenson F, Ong BN, et al. Achieving change in primary care-causes of the evidence to practice gap: systematic reviews of reviews. Implement Sci 2016;11:40

94. Yu J, Shah BM, Ip EJ, Chan J. A Markov model of the cost-effectiveness of pharmacist care for diabetes in prevention of cardiovascular diseases: evidence from Kaiser Permanente Northern California. J Manag Care Pharm 2013;19:102-114

95. Chan CW, Siu SC, Wong CK, Lee VW. A pharmacist care program: positive impact on cardiac risk in patients with type 2 diabetes. J Cardiovasc Pharmacol Ther 2012;17:57-64

96. Tshiananga JK, Kocher S, Weber C, Erny-Albrecht K, Berndt K, Neeser K. The effect of nurse-led diabetes self-management education on glycosylated hemoglobin and cardiovascular risk factors: a meta-analysis. Diabetes Educ 2012;38:108-123

97. Evert AB, Boucher JL, Cypress M, et al.; American Diabetes Association. Nutrition therapy recommendations for the management of adults with diabetes. Diabetes Care 2013;36:3821-3842

98. Evert AB, Boucher JL. New diabetes nutrition therapy recommendations: what you need to know. Diabetes Spectr 2014;27:121-130

99. Baksi AK, Al-Mrayat M, Hogan D, Whittingstall E, Wilson P, Wex J. Peer advisers compared with specialist health professionals in delivering a training pro- 
gramme on self-management to people with diabetes: a randomized controlled trial. Diabet Med 2008;25:1076-1082

100. National Certification Board for Diabetes Educators. NCBDE-2017 certification examination for diabetes educators [Internet], 2017. Available from http://www. ncbde.org. Accessed 20 February 2017

101. American Association of Diabetes Educators. Candidate handbook for the American Association of Diabetes Educators (AADE) board certified advanced diabetes management (BC-ADM) examination [Internet], 2015. Available from https://castleworldwide.com/aade/ AppSystem/ 6/Public/Resource/AADE_ Candidate_Handbook. pdf. Accessed 4 April 2017

102. American Association of Diabetes Educators. Diabetes Educator practice levels [Internet]. Available from https:// www.diabeteseducator.org/practice/ practice-documents/diabetes-educatorpractice-levels. Accessed 4 June 2017

103. DengK, Ren Y, LuoZ, Du K, ZhangX, Zhang Q. Peer support training improved the glycemic control, insulin management, and diabetic behaviors of patients with type 2 diabetes in rural communities of central China: a randomized controlled trial. Med Sci Monit 2016;22:267-275

104. Anderson B, Sellers M, Warren N. Recognizing health education specialists' roles in diabetes prevention and management: a toolkit for diabetes self-management education [Internet]. Washington, DC, Society for Public Health Education. Available from http://www.sophe.org/ wp-content/uploads/2017/01/DiabetesSelfManagementHealthEducatorToolkit_Final. pdf. Accessed 20 February 2017

105. Centers for Disease Control and Prevention. Working together to manage diabetes: a toolkit for pharmacy, podiatry, optometry, and dentistry (PPOD) [Internet] Atlanta, GA, Centers for Disease Control and Prevention, U.S. Department of Health and Human Services; 2016. Available from https://www.cdc.gov/diabetes/ndep/toolkits/ ppod.html. Accessed 20 February 2017

106. American Association of Diabetes Educators. Community health workers in diabetes management and prevention: AADE practice synopsis [Internet]. Available from https:// www.diabetese ducator.org/docs/default-source/ default-document-library/communityhealth-workers-in-diabetes-managementand-prevention.$p d f$ ?sfvrsn $=0$. Accessed 12 June 2017

107. UniversityofTexas-Houston School of Public Health, Institute for Health Policy. Understanding scope and competencies: a contemporary look at the United States community health worker field: progress report of the Community Health Worker (CHW) Core Consensus (C3) Project: building national consensus on CHW core roles, skills and qualities [Internet], 2016. Available from https:// sph.uth.edu/
dotAsset/28044e61-fb10-41a2-bf3b07efa4fe56ae.pdf. Accessed 20 February 2017

108. Diabetes Prevention Program (DPP) Research Group. The Diabetes Prevention Program (DPP): description of lifestyle intervention. Diabetes Care 2002; $25: 2165-2171$

109. Gillett M, Dallosso H, Dixon S, et al. Delivering the Diabetes Education and Self Management for Ongoing and Newly Diagnosed (DESMOND) Programme for people with newly diagnosed type 2 diabetes: cost effectiveness analysis. BMJ 2010;341:c4093-c4093

110. Redman B. The Practice of Patient Education. 10th ed. St. Louis, MO, Mosby, 2007

111. Mulcahy K, Maryniuk M, Peeples M, et al. Diabetes self-management education core outcomes measures. Diabetes Educ 2003;29:768-770, 773-784, 787-788 passim

112. Reader D, Splett P, Gunderson EP; Diabetes Care and Education Dietetic Practice Group. Impact of gestational diabetes mellitus nutrition practice guidelines implemented by registered dietitians on pregnancy outcomes. J Am Diet Assoc 2006;106:1426-1433

113. Boucher JL, Evert A, Daly A, et al.; American Dietetics Association. American Dietetic Association revised standards of practice and standards of professional performance for registered dietitians (generalist, specialty, and advanced) in diabetes care. J Am Diet Assoc 2011;111:156-166. e1, 27

114. Tang TS, Gillard ML, Funnell MM, et al. Developing a new generation of ongoing diabetes self-management support interventions: a preliminary report. Diabetes Educ 2005;31:91-97

115. Funnell MM, Nwankwo R, Gillard ML, Anderson RM, Tang TS. Implementing an empowerment-based diabetes selfmanagement education program. Diabetes Educ 2005;31:53-61, 55-56, 61

116. Piatt GA, Orchard TJ, Emerson S, et al. Translating the chronic care model into the community: results from a randomized controlled trial of a multifaceted diabetes care intervention. Diabetes Care 2006;29:811-817

117. American Association of Diabetes Educators. The scope of practice, standards of practice, and standards of professional performance for diabetes educators

[Internet]. http://www .diabetesed.net/ page/_files/Standards-of-Practice-

ADA-2011.PDF. Accessed 26 February 2017

118. Norris SL. Health-related quality of life among adults with diabetes. Curr Diab Rep 2005;5:124-130

119. Herman AA. Community health workers and integrated primary health care teams in the 21st century. J Ambul Care Manage 2011;34:354-361
120. Weinger K, Beverly EA, Lee Y, Sitnokov L, Ganda OP, Caballero AE. The effect of a structured behavioral intervention on poorly controlled diabetes: a randomized controlled trial. Arch Intern Med 2011;171:1990-1999

121. Norris SL, Lau J, Smith SJ, Schmid $\mathrm{CH}$, Engelgau MM. Self-management education for adults with type 2 diabetes: a meta-analysis of the effect on glycemic control. Diabetes Care 2002;25:1159-1171

122. American Association of Diabetes Educators. AADE7 Self-Care Behaviors, American Association of Diabetes Educators (AADE)Position Statement [Internet], 2014. Available from https://www. diabeteseducator.org/docs/default-source/ legacy-docs/_resources/pdf/publications/ aade7_position_statement_final.pdf? sfvrsn=4. Accessed 1 June 2017

123. Glazier RH, Bajcar J, Kennie NR, Willson K. A systematic review of interventions to improve diabetes care in socially disadvantaged populations. Diabetes Care 2006;29:1675-1688

124. Magee M, Bowling A, Copeland J, Fokar A, Pasquale P, Youssef G. The ABCs of diabetes: diabetes self-management education program for African Americans affects A1C, lipid-lowering agent prescriptions, and emergency department visits. Diabetes Educ 2011;37:95-103

125. Cavanaugh K, Huizinga MM, Wallston $\mathrm{KA}$, et al. Association of numeracy and diabetes control. Ann Intern Med 2008:148:737-746

126. Rothman RL, DeWalt DA, Malone $\mathrm{R}$, et al. Influence of patient literacy on the effectiveness of a primary care-based diabetes disease management program. JAMA 2004;292:1711-1716

127. Schillinger D, Grumbach K, Piette J, et al. Association of health literacy with diabetes outcomes. JAMA 2002;288:475-482

128. Inzucchi SE, Bergenstal RM, Buse JB, et al.; American Diabetes Association (ADA); European Association for the Study of Diabetes (EASD). Management of hyperglycemia in type 2 diabetes: a patient-centered approach: position statement of the American Diabetes Association (ADA) and the European Association for the Study of Diabetes (EASD). Diabetes Care 2012;35:1364-1379

129. Coulter A, Entwistle VA, Eccles A, Ryan S, Shepperd S, Perera R. Personalised care planning for adults with chronic or long-term health conditions. Cochrane Database Syst Rev 2015; 3:CD010523

130. American Association of Diabetes Educators. AADE position statement. Individualization of diabetes selfmanagement education. Diabetes Educ 2007;33:45-49

131. Patel R, Chang T, Greysen SR, Chopra $\mathrm{V}$. Social media use in chronic disease: a systematic review and novel taxonomy. Am J Med 2015; 128:1335-1350 
132. Schellenberg ES, Dryden DM,

Vandermeer B, Ha C, Korownyk C. Lifestyle interventions for patients with and at risk for type 2 diabetes: a systematic review and meta-analysis. Ann Intern Med 2013;159:543-551

133. Gucciardi E, Chan VW, Manuel L, Sidani S. A systematic literature review of diabetes self-management education features to improve diabetes education in women of Black African/ Caribbean and Hispanic/Latin American ethnicity. Patient Educ Couns 2013;92:235-245

134. Berkman ND, Sheridan SL, Donahue $\mathrm{KE}$, et al. Health literacy interventions and outcomes: an updated systematic review. Evid Rep Technol Assess (Full Rep) 2011;Mar:1-941

135. Attridge M, Creamer J, Ramsden M, Cannings-John R, Hawthorne K. Culturally appropriate health education for people in ethnic minority groups with type 2 diabetes mellitus. Cochrane Database Syst Rev 2014;Sep 4: CD006424

136. Channon SJ, Huws-Thomas MV, Rollnick S, et al. A multicenter randomized controlled trial of motivational interviewing in teenagers with diabetes. Diabetes Care 2007;30:1390-1395

137. Ha Dinh TT, Bonner A, Clark R, Ramsbotham J, Hines S. The effectiveness of the teach-back method on adherence and self-management in health education for people with chronic disease: a systematic review. JBI Database Syst Rev Implement Reports 2016;14:210-247

138. Welschen LM, van Oppen P, Bot SD, Kostense PJ, Dekker JM, Nijpels G. Effects of a cognitive behavioural treatment in patients with type 2 diabetes when added to managed care; a randomised controlled trial. J Behav Med 2013; 36:556-566

139. Parchman ML, Zeber JE, Palmer RF. Participatory decision making, patient activation, medication adherence, and intermediate clinical outcomes in type 2 diabetes: a STARNet study. Ann Fam Med 2010;8:410-417

140. Lorig K, Ritter PL, Turner RM, English K, Laurent DD, Greenberg J. A diabetes self-management program: 12-month outcome sustainability from a nonreinforced pragmatic trial. J Med Internet Res 2016;18:e322

141. Boren SA. AADE7TM Self-care Behaviors: systematic reviews. Diabetes Educ 2007;33:866-871, 871

142. Gandhi GY, Kovalaske M, Kudva Y, et al. Efficacy of continuous glucose monitoring in improving glycemic control and reducing hypoglycemia: a systematic review and meta-analysis of randomized trials. J Diabetes Sci Technol 2011;5: 952-965

143. Floyd B, Chandra P, Halls, et al. Comparative analysis of the efficacy of continuous glucose monitoring and self-monitoring of blood glucose in type 1 diabetes mellitus. J Diabetes Sci Technol 2012;6:1094-1102

144. Schnell O, Alawi H, Battelino T, et al. Self-monitoring of blood glucose in type 2 diabetes: recentstudies. J Diabetes Sci Technol 2013;7:478-488

145. Hamine S, Gerth-Guyette E, Faulx D, Green BB, Ginsburg AS. Impact of mHealth chronic disease management on treatment adherence and patient outcomes: a systematic review. J Med Internet Res 2015;17:e52

146. Saffari M, Ghanizadeh G, Koenig HG. Health education via mobile text messaging for glycemic control in adults with type 2 diabetes: a systematic review and metaanalysis. Prim Care Diabetes 2014;8:275-285

147. Hall AK, Cole-Lewis H, Bernhardt JM. Mobile text messaging for health: a systematic review of reviews. Annu Rev Public Health 2015;36:393-415

148. Beverly EA, Ganda OP, Ritholz MD, et al. Look who's (not) talking: diabetic patients' willingness to discuss self-care with physicians. Diabetes Care 2012:35:1466-1472

149. Flodgren G, Rachas A, Farmer AJ, Inzitari M, Shepperd S. Interactive telemedicine: effects on professional practice and health care outcomes. Cochrane Database Syst Rev 2015 (9):CD002098

150. Pal K, Eastwood SV, Michie S, et al. Computer-based diabetes self-management interventions for adults with type 2 diabetes mellitus. Cochrane Database Syst Rev 2013 (3):CD008776

151. Mulvaney SA, Rothman RL, Wallston KA, Lybarger C, Dietrich MS. An internet-based program to improve self-management in adolescents with type 1 diabetes. Diabetes Care 2010;33:602-604

152. Osborn CY, Mayberry LS, Mulvaney SA, Hess R. Patient web portals to improve diabetes outcomes: a systematic review. Curr Diab Rep 2010; 10:422-435

153. Moore SM, Schiffman R, WaldropValverde D, et al. Recommendations of common data elements to advance the science of self-management of chronic conditions. J Nurs Scholarsh 2016;48: 437-447

154. Yu CH, Parsons J, Mamdani M, et al. Designing and evaluating a web-based self-management site for patients with type 2 diabetes-systematic website development and study protocol. BMC Med Inform Decis Mak 2012;12:57

155. Plotnikoff RC, Costigan SA, Karunamuni ND, Lubans DR. Communitybased physical activity interventions for treatment of type 2 diabetes: a systematic review with meta-analysis. Front Endocrinol (Lausanne) 2013;4:3

156. Ali MK, Echouffo-Tcheugui J, Williamson DF. How effective were lifestyle interventions in real-world settings that were modeled on the Diabetes Prevention
Program? Health Aff (Millwood) 2012; 31:67-75

157. Dunkley AJ, Charles K, Gray LJ, Camosso-Stefinovic J, Davies MJ, Khunti $\mathrm{K}$. Effectiveness of interventions for reducing diabetes and cardio-vascular disease risk in people with metabolic syndrome: systematic review and mixed treatment comparison meta-analysis. Diabetes Obes Metab 2012;14:616-625

158. Stevens JW, Khunti K, Harvey R, et al. Preventing the progression to type 2 diabetes mellitus in adults at high risk: a systematic review and network metaanalysis of lifestyle, pharmacological and surgical interventions. Diabetes Res Clin Pract 2015;107:320-331

159. Wang J, Siminerio LM. Educators insights in using chronicle diabetes: a data management system for diabetes education. Diabetes Educ 2013; 39:248-254

160. Debussche X, Rollot O, Le Pommelet $\mathrm{C}$, et al. Quarterly individual outpatients lifestyle counseling after initial inpatients education on type 2 diabetes: the REDIA Prev-2 randomized controlled trial in Reunion Island. Diabetes Metab 2012;38:46-53

161. Ferrara A, Hedderson MM, Ching J, Kim C, Peng T, Crites YM. Referral to telephonic nurse management improves outcomes in women with gestational diabetes. Am J Obstet Gynecol 2012;206:491.e1-491.e5

162. Dale JR, Williams SM, Bowyer V. What is the effect of peer support on diabetes outcomes in adults? Asystematic review. Diabet Med 2012;29:1361-1377

163. Tan P, Chen HC, Taylor B, Hegney D. Experience of hypoglycaemia and strategies used for its management by community-dwelling adults with diabetes mellitus: a systematic review. Int J Evid-Based Healthc 2012;10:169-180

164. Tang T, Ayala G, Cherrington A, Rana G. A review of volunteer-based peer support interventions in diabetes. Diabetes Spectr 2011;24: 85-98

165. Torenholt R, Schwennesen N, Willaing I. Lost in translation-the role of family in interventions among adults with diabetes: a systematic review. Diabet Med 2014;31:15-23

166. Knight AW, Ford D, Audehm R, Colagiuri S, Best J. The Australian Primary Care Collaboratives Program: improving diabetes care. BMJ Qual Saf 2012;21:956-963

167. Boger E, Ellis J, Latter S, et al. Selfmanagement and self-management support outcomes: a systematic review and mixed research synthesis of Stakeholder views. PLoS One 2015;10:e0130990

168. Miller CK, Bauman J. Goal setting: an integral component of effective diabetes care. Curr Diab Rep 2014;14:509

169. Fleming SE, Boyd A, Ballejos M, et al. Goal setting with type 2 diabetes: a hermeneutic analysis of the experiences of diabetes educators. Diabetes Educ 2013;39:811-819 
170. Teal CR, Haidet P, Balasubramanyam AS, Rodriguez E, Naik AD. Measuring the quality of patients' goals and action plans: development and validation of a novel tool. BMC Med Inform Decis Mak 2012;12:152

171. Bovend'Eerdt TJ, Botell RE, Wade DT. Writing SMART rehabilitation goals and achieving goal attainment scaling: a practical guide. Clin Rehabil 2009;23:352-361

172. Department of Health \& Human Services. Quality Payment Program [Internet]. Available from https://qpp.cms. gov/. Accessed 20 February 2017

173. Institutefor Healthcare Improvement. Available from http://www.ihi.org. Accessed 4 June 2017

174. RE-AIM - Reach Effectiveness Adoption Implementation Maintenance. Available from http://re-aim.org/. Accessed 4 June 2017

175. Polonsky WH, Fisher L, Earles J, et al. Assessing psychosocial distress in diabetes: development of the Diabetes Distress Scale. Diabetes Care 2005;28:626-631
176. Topp CW, Østergaard SD, Søndergaard $\mathrm{S}$, Bech P. The WHO-5 Well-Being Index: a systematic review of the literature.

Psychother Psychosom 2015;84:167-176

177. Peyrot M, Burns KK, Davies M, et al. Diabetes Attitudes Wishes and Needs 2 (DAWN2): a multinational, multi-stakeholder study of psychosocial issues in diabetes and person-centred diabetes care. Diabetes Res Clin Pract 2013;99: 174-184

178. Polonsky WH, Anderson BJ, Lohrer PA, et al. Assessment of diabetes-related distress. Diabetes Care 1995;18:754-760

179. Markowitz JT, Volkening LK, Butler DA, Laffel LM. Youth-perceived burden of type 1 diabetes. J Diabetes Sci Technol 2015;9:1080-1085

180. Weissberg-Benchell J, AntisdelLomaglio J. Diabetes-specific emotional distress among adolescents: feasibility, reliability, and validity of the problem areas in diabetes-teen version. Pediatr Diabetes 2011;12(4pt1):341-344
181. Ritter PL, Lorig K, Laurent DD.

Characteristics of the Spanish- and Englishlanguage self-efficacy to manage diabetes scales. Diabetes Educ 2016; 42:167-177

182. Weinger K, Butler HA, Welch GW, La Greca AM. Measuring diabetes self-care: a psychometric analysis of the Self-Care Inventory-Revised with adults. Diabetes Care 2005;28:1346-1352

183. Toobert D, Hampson S, Glasgow R. The summary of diabetes self-care activities measure. Diabetes Care 2000;23:943-950

184. Paxton AE, Strycker LA, Toobert DJ, Ammerman AS, Glasgow RE. Starting The Conversation: performance of a brief dietary assessment and intervention tool for health professionals. Am J Prev Med 2011:40:67-71

185. Chew LD, Bradley KA, Boyko EJ. Brief questions to identify patients with inadequate health literacy. Fam Med 2004:36:588-594

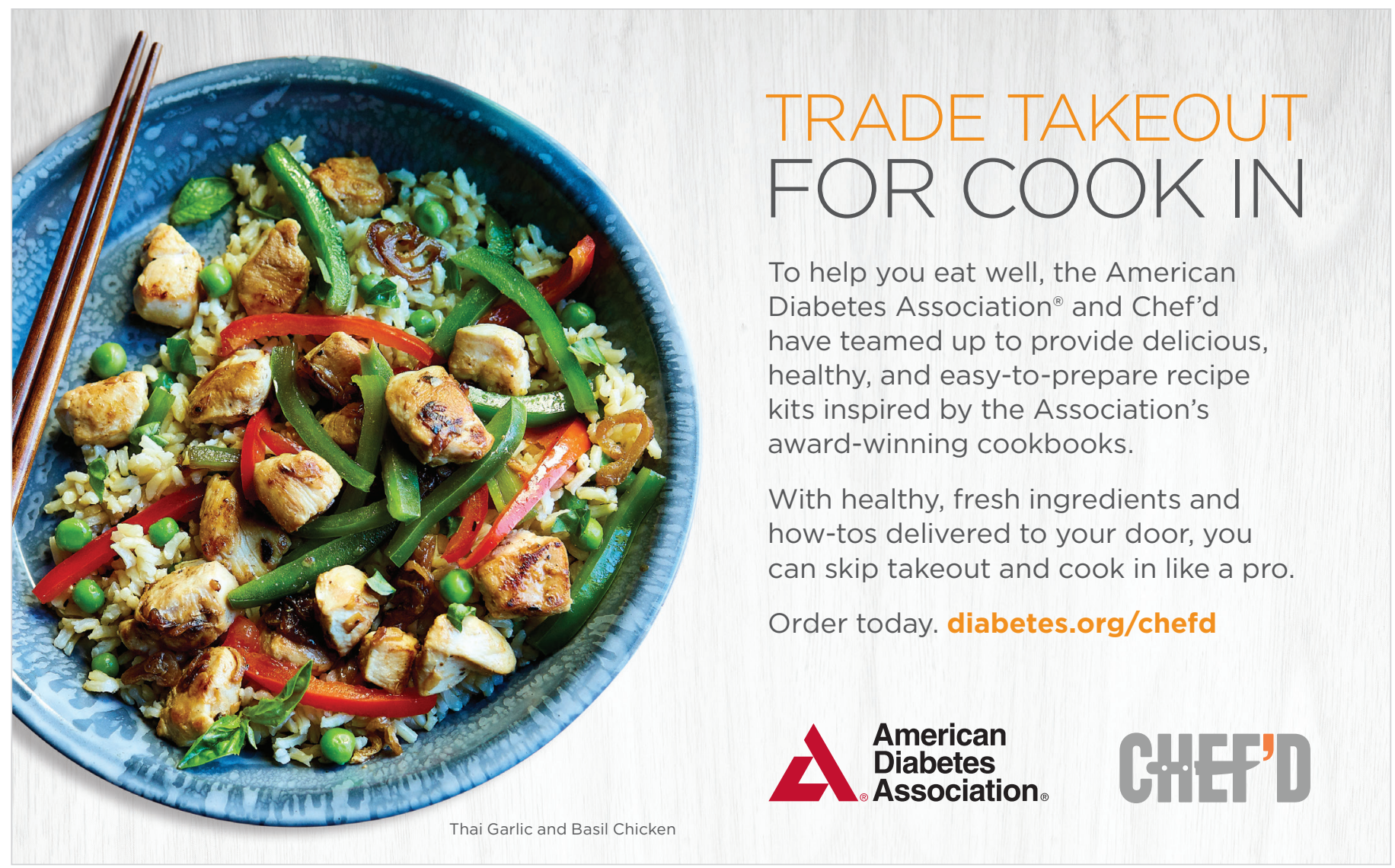

